\title{
Introduction: Why Revisit Intimacy?
}

\author{
Sertaç Sehlikoglu, University of Cambridge \\ Aslı Zengin, Brandeis University
}

\begin{abstract}
Intimacy is tightly bound up with notions of privacy, sexuality, proximity and secrecy, and with dynamics of sensual and affective attachments and forms of desire. It is therefore integral to the formation of human selves and subjectivities, as well as communities, publics, collectives and socialities. The articles in this Special Section all offer an anthropological inquiry into intimacy, seeking a conceptual formulation that might capture its actual operations, the ways intimacy is done in talk and action. They thus contribute ethnographically to ongoing anthropological debates about intimacy, and explore how multiple domains and forms of intimacies are defined, shaped, constructed and transformed across different social worlds.
\end{abstract}

Keywords: affect, belonging, family, intimacy, proximity, secrecy, state

Intimacy is a difficult but enthralling object of enquiry, located somewhere in what it is to be human in relation to both human and non-human subjects, and to ideas of the social, of time and of space. Everything anthropology studies, in that sense, could be related to intimacy. Intimacy has multiple elements to its formation, distribution and organization, which make its meaning ambiguous. As Henrietta Moore (2014) has rightly asked: 'If intimacy is the answer, then what is the question?' Moore has suggested a careful approach to the notion since, due to its awkward relationship with language, its apparently secretive nature and proximity to our sense of self, 'intimacy' easily creates a near-aphasic, polysemic confusion. The careful approach required is one, we argue, that involves an ethnographically grounded formulation.

In this themed Special Section, we offer an anthropological inquiry into intimacy, and seek a conceptual formulation that captures its operations: how it creates boundaries as well as flows and transitions between bodies, selves and groups. Intimacy forges distances and proximities as well as bonds and attachments, and creates new meanings (Stoler 2008). This analytical potential inspires as much as guides us in our endeavour to conceptualize intimacy beyond the limits of sexuality. Dominant in certain sociological approaches to intimacy, the sexual realm has become the primary definitive dimension of 'the intimate' (D'emilio and Freedman 1988; Giddens 1992; Weeks 1998; Gross and Simmons 2002; Attwood 2006). It is possible to argue that the fascination and thus preoccupation with sexual intimacy is partly related to the tendency to perceive it as 'a premier site of detraditionalization in the late modern era' (Gross 2005). 
This approach to the intimate has contributed to the everyday makings of normalcies through the regulation of sex, with an intimate act often described as an affectionate act taking place between couples: kissing, caressing, holding hands, intercourse and so forth. A preoccupation with sexuality, coupling and relationships in studies focusing on intimacy risks limiting our horizons concerning the very nature of the intimate and the way it operates in everyday life at moments when we make sense of emotions such as affection and/or violence. This preoccupation then works against a critical, non-Eurocentric recalibration of the term, as revealed by critical engagements with the previous sociological work cited (Jamieson 1999; Roseneil and Budgeon 2004).

One anthropological approach to an expansion of the scope of intimacy as an analytical category owes its vigour to studies of sexuality and the state together (Cooper 1995; Kim et al. 2005; Sharma 2006; Brownell and Besnier 2013), as well as to studies of sexuality and nation (Boellstorff 2004), and a stream of literature that problematizes how regulations on marriage and family both reinforce normalcies and suggest new ones (Mody 2008). Works by Ann Laura Stoler (2002), Lauren Berlant (1997) and Elizabeth Povinelli $(2002,2006)$ have given extensive consideration to the ways in which states have politicized intimate matters - conjugality, family, domesticity, sexuality in colonial, postcolonial and neoliberal times. Through their policies and regulations, states are heavily invested in drawing moral and sexual boundaries in individual and social lives. Berlant (1997), for example, shows us how the definition of a 'good' republican citizen in the U.S. context relies on people's investment of their energies in work and family making and their avoidance of broader social and economic problems. A dedication to protecting their ordinary lives becomes the condition of inhabiting a secure space as citizens.

Povinelli (2002), on the other hand, draws on the Aboriginal people's land-claim documents in Australia to examine how the 'modern' definition of intimacy forecloses the recognition and legitimacy of certain subjectivities and intimacies that shape these people's investments in their identities. In a later work, she explores the governance of intimacy at the intersection of neoliberal agendas and multicultural discourses across settler colonies (Australia, the United States, Canada) along with the indigenous worlds and their local notions of corporeality, proximity, affect, place, context and spirituality; she emphasizes 'the uneven distribution of the flesh - the creation of life-worlds, death-worlds, and rotting worlds', to describe love, intimacy and sexuality as matters of 'geography, history, culpability, and obligation; the extraction of wealth and distribution of life and death; hope and despair; and the seemingly self-evident fact and value of freedom' (Povinelli 2006: 8, 10). This framework is useful for understanding the work of state power in recognizing or disapproving particular intimacies at the intersection of neoliberal agendas and multicultural discourses.

The entangled relationship of intimacy and nation-state shows itself also in discourses and practices of national inclusion and identification. This identification may rely on a shared knowledge of, and affective attachments to, certain cultural stereotypes that are often considered a 'source of external embarrassment' because the official representation and reification of these stereotypes usually diverge from their everyday perception and presentation (Herzfeld 2005). However, this discrepancy is constitutive of what Michael Herzfeld conceptualizes as a 'cultural intimacy' (ibid) established among the insiders of 
a national culture, who commonly share these unofficial perspectives which are closed to outsiders. In his article in the Special Section that follows here, Jeremy Walton works with this concept of 'cultural intimacy' to discuss the recent Croatian and Turkish state projects of inter-religious tolerance. A shared war victimhood between Catholic Croats and Muslim Bosnians and a primordial siblinghood between Sunni and Alevi Muslims build the ground for the public perception of religious difference in these contexts. However, by blending the notion of cultural intimacy with spatial intimacy, Walton shows how such public staging actually conceals the politics of religious differences.

Building on such discussions, it is possible to question the tendency to equate sexuality and intimacy and to suggest that this immediate connection is very much bound up with modernity (D’Emilio and Freedman 1988; Lane 1999), with issues related to settler colonialism, nation-state formation and neoliberalism (Povinelli 2006; Stoler 2008; Lowe 2015).

In fact, any form and instance of relatedness can be interpreted as intimate in its capacity to shape people's senses of selves, their feelings, their attachments and their identifications. In her formulation of the concept, Ara Wilson suggests that 'the concept of intimacy captures deeply felt orientations and entrenched practices that make up what people consider to be their "personal" and "private" lives and their interior selves, and includes positively valued feelings like affection but also problematic feelings like fear and disgust' (Wilson 2012: 32). Following this view, it seems that a very great deal of our lives could ultimately turn out to be about intimacy. Even if it may seem the opposite, it is this very aspect that can function as the strength of intimacy as an interesting analytical rubric.

The 'depth' of intimacy is related to its connection to our very sense of selves. Christopher Lane points out that strong psychoanalytic models can incorporate social factors that reveal the makings of intimacy (Lane 1999). Indeed, as Mendelsohn (1982) famously points out, intimacy is both an intra-psychic as well as an interpersonal process. It is about how we make sense of our selves and connect with the outside world, with others; as Mendelsohn says, 'One must first be intimate with oneself before one can be intimate with others' (ibid.: 39). This is why the terminology used for intimacy in different contexts reveals the operations of subjectivity and intersubjectivity. In the articles that follow, this intersectionality between the self and others reveals itself in Walton's formulation of primordial kinship and Sehlikoglu's analysis of the culture of mahremiyet. Focusing on similar geographies, these contributors engage with the ways in which people make sense of the intimate by using terms and concepts derived from kinship and/or marriage as a form of public recalibration of intimacy. Moreover, in Sehlikoglu's account, when the culture of mahremiyet presents itself in the form of a creationist normativity (fitrat), it connects the perception of the gendered self to a larger cosmology, as a way of confirming those norms and positioning the self in relation to them.

If intimacy is about connections and boundaries as well as secrecy and privacy, then at a time when the nature of connections is changing, how does what we refer to as 'globalization' trigger tensions and anxieties related to borders (Appadurai 1997) and thus complicate ideas concerning the intimacy of couples, families and state? Maïté Maskens' contribution tackles this question through an investigation of the intimate 
border policies and practices of the Belgian state, and explores how state actors in civil registry offices distinguish true from fake marriages in immigration applications. The evaluation of bi-national marriages (marriages of people from two different nationalities) by public authorities becomes an institutionally intimate domain in which the state draws boundaries between good and bad, between modern and traditional and between acceptable and unacceptable forms of shared intimacy. Thus, Maskens argues, national territorial borders are reaffirmed as also boundaries of the moral and the intimate.

In a similar vein, Moore $(2011,2014)$ draws our attention to new intimacies that are calibrated through new connections enabled by what is often referred to as 'globalization'. Indeed, intimacy can work as a powerful analytical concept to understand economic and global relations. With the intensification of mobility and exchange and the constantly increasing role of technology in our everyday lives, transnational forms of intimacy have become ever more possible and prominent in social and economic environments of domesticity, sexuality and care - and a vast amount of anthropological research shows that these transnational intimacies are highly shaped by and embedded in specific social relations of inequality, based on perceived gender, ethnic, racial, national and class differences (see Brennan 2001; Ehrenreich and Hochschild 2004; Parrenas 2005; Wilson 2012). Valerio Simoni's work in this issue contributes to these discussions by focusing on intimate relationships between Cubans and tourists, and among Cuban migrants in Barcelona (Spain), examining how his informants define and use ideal types of 'true' and 'fake' intimacies to appraise their relations of love, kinship and friendship. Simoni's piece is crucial to further comprehend the role of historical and transnational factors in forming and shaping categorizations of belonging and exclusion, normalcy and exception, and morality and immorality in everyday intimate interactions.

Another interesting aspect of intimacy that emerges in three of the pieces here (Maskens, Simoni, Shapiro) is that of intimacy as pretension and performance. How might one provide evidence of intimacy, especially when it is one of the least describable experiences in human life? The most intimate moment is the most difficult to describe, one that poets dwell on and novelists are haunted by - and which seems to enchant ethnographers too. Yet it is also something one may question within the lived experienced itself: 'Is s/he genuine? Or is s/he faking it?' The expression of intimacy is guided by cultural codes, what ought to be hidden and what ought to be revealed, how intimacy should be performed or expressed. What kinds of discrepancies, vulnerabilities and even ferocities are created, then, when the sincerity of intimacy is questioned by third parties, state officers and others?

Finally, applying a reflexive imperative, we should perhaps add a few words on the intimate nature of fieldwork. The elements and dynamics of intimacy that we have already mentioned are constitutive not only of the texture of our informants' everyday lives but also - of course, inescapably - of the relationship between the ethnographer and the field. The anthropological tradition of participant observation, undertaken in order to gain an intimate knowledge, demands the gradual formation of close connections, bonds and exchanges of various kinds. As ethnographers go deeper into the everyday life of their informants, they move along a variety of domains of intimacy 
that construct the very logic of in-depth fieldwork. This 'deep' knowledge of the field is also a realm of the intimate. Permission to enter, or gaining access to, the necessary domains of intimacy also has also a transformative power, defining and redefining the role and meaning of the ethnographer in her/his informants' lives and, more broadly, that of the community studied.

\section{Acknowledgements}

We would like to thank both Newnham College and the Division of Social Anthropology, University of Cambridge, for their financial support of the May 2014 workshop 'Probing the Intimate: Cross-Cultural Queries of Proximity and Beyond', on which this Special Section is based (a workshop organized by the two guest editors along with a third convener, Marlene Schäfers). Our thanks are due to the participants in that workshop and to all the very helpful reviewers of these articles.

\section{References}

Appadurai, A. 1997. Discussion: Fieldwork in the Era of Globalization. Anthropology and Humanism 22(1): 115-118.

Attwood, F. 2006. Sexed up: Theorizing the Sexualization of Culture. Sexualities 9(1): 77-94.

Berlant, L.G. 1997. The Queen of America Goes to Washington City: Essays on Sex and Citizenship. Durham: Duke University Press.

Boellstorff, T. 2004. Playing back the Nation: Waria, Indonesian Transvestites. Cultural Anthropology 19(2): 159-195.

Brennan, D. 2001. Tourism in Transnational Places: Dominican Sex Workers and German Sex Tourists Imagine One Another. Identities 7(4): 621-663.

Brownell, S., \& N. Besnier. 2013. Gender and Sexuality. In The Handbook of Sociocultural Anthropology (eds) J.G. Carrier \& D.B. Gewertz, 239-258. London: Bloomsbury.

Cooper, D. 1995. Power in Struggle: Feminism, Sexuality and the State. Cambridge: Cambridge University Press.

D’Emilio J., \& E.B. Freedman. 1988. Intimate Matters: A History of Sexuality in America. Chicago: University of Chicago Press.

Ehrenreich, B., \& A.R. Hochschild. 2004. Global Woman: Nannies, Maids, and Sex Workers in the New Economy. New York: Metropolitan Books/Henry Holt and Co.

Giddens, A. 1992. The Transformation of Intimacy: Sexuality, Love and Eroticism in Modern Societies. Cambridge: Polity Press.

Gross, N. 2005. The Detraditionalization of Intimacy Reconsidered. Sociological Theory 23(3): 286-311.

Gross, N. \& S. Simmons. 2002. Intimacy as a Double-Edged Phenomenon? An Empirical Test of Giddens. Social Forces 81(2): 531-555.

Herzfeld, M. 2005. Cultural Intimacy: Social Poetics in the Nation-state. New York: Routledge.

Jamieson, L. 1999. Intimacy Transformed? A Critical Look at the 'Pure Relationship'. Sociology 33(3): 477-494.

Kim, H.S., J. Puri \& H. Kim-Puri. 2005. Conceptualizing Gender-Sexuality-State-Nation: An Introduction. Gender and Society 19(2): 137-159.

Lane, C. 1999. The Burdens of Intimacy: Psychoanalysis and Victorian Masculinity. Chicago: University of Chicago Press.

Lowe, L. 2015. Intimacies of Four Continents. Durham: Duke University Press. 
Mendelsohn, R. 1982. Intimacy in Psychoanalysis. In Intimacy (eds) M. Fisher \& G. Stricker, 39-51. New York: Springer.

Mody, P. 2008. The Intimate State: Love-marriage and the Law in Delhi. New Delhi: Routledge. Moore, H.L. 2011. Still Life: Hopes, Desires and Satisfactions. Cambridge: Polity Press.

Moore, H.L. 2014. If Intimacy is the Answer, Then What is the Question? Paper presented at the workshop entitled 'Probing the Intimate: Cross-Cultural Queries of Proximity and Beyond', University of Cambridge, May 2014.

Parrenas, R.S. 2005. Children of Global Migration: Transnational Families and Gendered Woes. Stanford: Stanford University Press.

Povinelli, E.A. 2002. Notes on Gridlock: Genealogy, Intimacy, Sexuality. Public Culture 14(1): 215-238.

Povinelli, E.A. 2006. The Empire of Love: Toward a Theory of Intimacy, Genealogy, and Carnality. Durham: Duke University Press.

Roseneil, S., \& S. Budgeon. 2004. Cultures of Intimacy and Care beyond 'the Family': Personal Life and Social Change in the Early 21st Century. Current Sociology 52(2): 135-159.

Sharma, A. 2006. Crossbreeding Institutions, Breeding Struggle: Women's Empowerment, Neoliberal Governmentality, and State (Re)formation in India. Cultural Anthropology 21(1): 60-95.

Sointu E., \& L. Woodhead. 2008. Spirituality, Gender, and Expressive Selfhood. Journal for the Scientific Study of Religion 47(2): 259-276.

Stoler A. 2002. Carnal Knowledge and Imperial Power: Race and the Intimate in Colonial Rule. Berkeley, CA: University of California Press.

Stoler A. 2008. Imperial Debris: Reflections on Ruins and Ruination. Cultural Anthropology 23(2): 191-219.

Weeks, J. 1998. The Sexual Citizen. Theory, Culture \& Society 15(3): 35-52.

Wilson, A. 2012. Intimacy: A Useful Category of Transnational Analysis. In The Global and the Intimate: Feminism in Our Time (eds) G. Pratt \& V. Rosner, 31-56. New York: Columbia University Press.

Sertaç Sehlikoglu is an affiliated lecturer at the University of Cambridge. Her research focuses on gender, sexuality, the Middle East, subjectivity and self-making in general, and on related issues in Turkey in particular. Her work has been published in edited collections and in several journals including Leisure Studies, Feminist Media Studies, and The Journal of Middle East Women's Studies.

Aslı Zengin is an Allen-Berenson Postdoctoral Fellow in Women's, Gender, and Sexuality Studies at Brandeis University. Her recent publications include 'Sex for Law, Sex for Therapy: Pre-Sex Reassignment Surgical Therapy Sessions of Trans People in Istanbul', Anthropologica, 2014, 56(1): 55-68. 